\title{
Investigation of Relationship between Infertility Stress, Coping Styles and Perceived Social Support with Marital Satisfaction in Infertile Women
}

\author{
*Roshanak Roshani Ahrabi \\ Department of General Psychology, Guilan Science and Research Branch, Islamic Azad University, Rasht, Iran \\ Department of General Psychology, Rasht Branch, Islamic Azad University, Rasht, Iran \\ *Corresponding Author E-mail: Mrv19792000@gmail.com
}

Bahman Akbari

Doi:10.5901/mjss.2015.v6n3s2p754

Department of General psychology, Rasht Branch, Islamic Azad University, Rasht, Iran

\begin{abstract}
The present research aims to investigate the relationship between infertility stress, perceived social support and coping styles with marital satisfaction in infertile women. the statistical population of the research included all infertile women in Tehran City in 2013. 100 infertile women who had referred to Center for Infertility in Imam Khomeini Hospital in the second half of this year were selected by means of accessible sampling method. Newton's infertility stress index, Enrich's marital satisfaction questionnaire, Zimenth's multidimensional scale for perceived social support and short version of Andler and parker's stressful situations coping questionnaire were instruments for data collection in this research. Furthermore, Pearson correlation coefficient and stepwise regression analysis were used for data analysis. the results of the research showed that there is a negative significant relationship between infertility stress and emotion-based coping with marital satisfaction. On the other hand, perceived social support has a positive and significant relationship with marital satisfaction in infertile individuals. Furthermore, the results showed that marital satisfaction can be predicted by dimensions like relationship concern, important others, emotion-based coping, need for being a parent and sexual concern.
\end{abstract}

Keywords: infertility stress, coping methods, perceived social support, marital satisfaction.

\section{Introduction}

Family is an entity which is formed by marriage. However, marital compatibility and satisfaction are more important than marriage itself (Ahmadi, 2005). Satisfaction and marital satisfaction are wide concepts for identification of level of happiness and stability of a relationship (Wigel, Balad and Deboura, 1999). Furthermore, marital satisfaction concerns mental feelings (internal feelings) of couples on marital relationship and marital satisfaction refers to variables which include marital satisfaction, relationship, prosperity and satisfaction (Lewis and Spaneer, 1980; as quoted from BaghbanSichani et al, 2007). Marital satisfaction becomes important when different aspects affect couples relationships. Infertility is a stressful and tense factor which can affect the quality of relations (Yaghmayee, Mohammadi and AlaviMajd, 2009). The results of different studies (Benazoun, Right and Sabourin, 1992; Androuz, Abi and Halman, 1992; MolaeeNejad, Jafarpour, and Jahanfar and Jamshidi, 2000) showed that an increase in stress resulted from infertility may cause disorders in marital relations and reduce women's marital satisfaction. Furthermore, the results showed that infertility is more stressful in women than men (patch, Dankel-Keter and Kristians, 2002; Peterson, 2002; Li, San and Kavou, 2001). Individuals use different coping strategies when confronted with stress and psychological pressure. Studies on comparison of different stressful situations showed that stressor features play important roles in determination of coping responses (Delongis and Holtzman, 2005; Li-Bagli, peris and Delongis, 2005; Obrian and Delongis, 1996). When a tense factor like infertility forms in a family, it is accompanied by a coping context in which coping responses take form. Mollazadeh et al (2002) conducted a research on coping styles and marital compatibility. They showed that coping strategies have relationship with marital compatibility and coping strategies can be considered as predicting variables for marital compatibility in woman and man level. Furthermore, in Benjamin, Giffen and Berdarin et al (2008)research which dealt with specific coping strategies of infertile women, the results showed that coping strategies are related to four indices of compatibility on of which is marital satisfaction. Selection of appropriate coping responses differs from one person to another person dependent on situational factors and personality factors. Meanwhile, social support is a situational factor which can influence coping responses (Solenro et al, 1999; Delongis and Holtzman, 2005). According to 
evidence, individuals who receive support from others and have high levels of perceived support and are satisfied with this support, have more efficient and more compatible in confronting with stressful situations (Delongis and Holtzman, 2005). This can play an important role in marital life (Mazaheri et al, 2001). In addition to the social support role in responses to subsequent coping forms, coping responses can play role in the next supportive processes. For instance, in Dragest and Lindestrom's research (2005) which dealt with women with the probability of breast cancer, the results showed that social support and coping strategies have relationship with each other and women who use aggressive defensive styles tend to receive weak social support. Akochkian et al (2008) also showed that as social support increases, use of effective coping styles to confront with stress also increases and ineffective methods are used less frequently. Social support can be a barrier against negative events of stressful environment or may be a negative impact which may heighten stress (Milt, 2002). Milt's research (2002) showed that support creation is the core aspect of marriage which also influences life satisfaction. Furthermore, the results of the research conducted by Abi, Halman and Androuz (1992) showed that widespread support and small marital conflicts are related to low infertility stress and attachment of wife and husband to each other reduces infertility-arisen stress (Farahani, 2001). Considering the presence of sociopsychological aspects of infertility (KaramiNouri et al, 2001) and the results of previous studies, it seems that infertility stress can reduce marital satisfaction of couples. However, on the other hand, coping strategies and social supports can act as a defense against stress and be accompanied by marital satisfaction stress. Therefore, the main question of the research is that: "whether, infertility stress, coping strategies and social support have relationship with marital satisfaction?

\section{Research Methodology}

The statistical population of the research included 2461 infertile women in Tehran City who had referred to the center for infertility research in Imam Khomeini Hospital in the second half of 2013. 100 patients were selected by means of accessible sampling method as sample size.

\section{Research Instruments}

Fertility problem inventory-FPI (Newton et al, 1999): this inventory is a multidimensional instrument and specifically deals with infertility stress management. The first questionnaire was designed by Newton, Sherrard\&Glovac (1999; as quoted from Alizadeh, 2005). After implementation for several times and considering the infertility literature, the questionnaire was converted into its present format and normalized on infertility treatment seekers aged 27-40 (Alizadeh, 2005; Gibson and mayers, 2002). FPI questionnaire contains 5 subscales: social concern (first 10 questions), sexual concern (next 8 questions), Relationship concern (the next 10 questions), Rejection of childfree lifestyle (the next 8 questions), and need for parenthood (last 10 questions). It also contains one general infertility stress index. This scale was scored based on 6point Likert scale from completely disagree to completely agree from 1 to 6 . Considering the fact that a high score in general stress indicates high stress in infertility, some questions $(1,2,5,6,10,12,13,21,28,29,30,31,33,34,35,36$, 43) were reverse-scored (1=completely agree, $2=$ to some extent agree, $3=$ very low agree, $4=v e r y$ low disagree, $5=$ to some extent disagree, and $6=$ completely disagree). The score of each subsidiary scale is obtained by adding the raw scores of the questions of each subsidiary scale. The total stress is obtained by adding all raw scores in all five scales. Maximum score for 10-question scales was 60 and minimum score for such scales was 10. For 8-question scales, the maximum score was 48 and minimum score was 8.

In Newton et al's research (1999; as quoted from Alizadeh, 2005), all 5 scales showed high validity. Cronbach's alpha coefficient for internal consistency was equal to 0.87 fo social concern, 0.77 for sexual concern, 0.82 for relationship subjects, 0.80 for rejection of childfree lifestyle, 0.84 for need for parenthood, and 0.93 for general stress. In Alizadeh research (2005), the reliability was equal to 0.78 for social concern, 0.77 for sexual concern and 0.78 for relationship concern, 0.75 for rejection of childfree lifestyle, 0.84 for need for parenthood and 0.91 for general stress. The degree to which each scale evaluates different things is investigated by means of measurement of internal consistency between the five scales. This validity is divergent. Internal consistency of all five scales is significant but its score is lower than mean value (Newton et al, 1999; as quoted from Alizadeh, 2005). Newton believed that although the questionnaire measures every dimension separately, all dimensions of infertility stress are related to each other (Alizadeh, 2005). Enrich Marital Satisfaction Questionnaires: the short form of this questionnaire was used for evaluation of the level of marital satisfaction in the respondents (Enrich, 1988, as quoted from Olson, 1996). This questionnaire is used for a detection instrument for couples who seek for marital consultancy or try to strengthen their marital relations (Soleimanian, 1994). It was used as a valid research instrument for measurement of marital life satisfaction in many studies (Sanayee, 
2000). Considering the numerous questions of the questionnaire (115 questions) which could bore the respondents, a short form of the questionnaire was prepared. To this end, first we calculated the correlation between all questions and the total questionnaire via correlation coefficient. Then, 47 questions which had high correlation were selected from different scales of the questionnaire. The reliability coefficient of the 47-question form was calculated on a 11-people group and it was equal to 0.95 . therefore, after final verification, Enrich's marital satisfaction questionnaire was used for estimation of marital satisfaction (Sanayee, 2000). In the short form, the calculated scores which were below 30 showed severe dissatisfaction of couples, scores between 30 and 40 showed dissatisfaction of couples, scores between 40 and 60 showed relative and average satisfaction of couples, scores between 60 and 70 indicated high satisfaction of couples and scores above 70 indicated excellent satisfaction of couples with marital relations. In this research, the total score of marital satisfaction was considered.

Multidimensional Scale of Perceived Social Support(MSPSS): this scale has a mental evaluation of the adequacy of social support. It was designed by Zimneth et al (1988) (as quoted from Shokri, 2009). This scale evaluates perceptions of social support in three resources of family, friends and important others. The questions 3-4-8-11evaluated family resource, questions 6-7-9-12 evaluated friends resource and questions 1-2-5-10 evaluated supportive source of important others. Maimum score for each scale was 20 and minimum score was 4. Use of MSPSS is highly recommended because it is easy to use and is cost-effective (Shokri, 2009). This scale contains 12 questions which are all designed based on Likert scale from completely disagree (1) to completely agree (5). The results of studies conducted by Zimenth et al $(1988$, as quoted from Shokri, 2009) aimed at investigation of psychometric features of the scale showed that this instrument is valid and reliable for investigation of perceived social support. The results of the research conducted by Braver, Emsly, Kid, Luchner and Sidat (2008, as quoted from Shokri, 2009) in investigation of psychometric features of multidimensional scale for perceived social support using confirmatory factor analysis showed that the structure of the three factors of MSPSS has a good fit with the data. the short form of Coping Inventory for Stressful Situations (CISS-SF): Andler and Parker (1990, as quoted from Shokri, 2009) designed this questionnaire to evaluate all types of coping strategies in stressful situations including problem-oriented coping methods, emotion-oriented coping styles and avoidant styles. It must be noted that the dominant method of every individual is determined considering his or her score in each of the three dimensions of coping styles. In other words, each of the behaviors which receives a higher score in the scale is considered as preferred coping style of the individual. All questions are based on 5-point Likert scale from never (1) to very much (5). In Cohen et al's research (2006; as quoted from Shokri, 2009), the coefficients of Cronbach's alpha and correlation coefficients of the test-retest of the subscales showed that CISS-SF is very valid. Andler and Parker (1990, as quoted from Sayyadi, 2008) calculated the reliability of problem-based, emotion-based and avoidant methods to be equal to $0.92,0.82$, and 0.85 for boys, respectively, and $0.90,0.85,0.82$ for girls. The short form of the questionnaire contains 21 questions and every 7 questions evaluate 1 question. Questions 1-4-7-9-15-18-21 evaluated avoidant coping method, questions 2-6-8-11-13-16-19 evaluated problem-based coping style and questions 35-10-12-14-17-20 evaluated emotion-based coping style. the maximum score for each method was 35 and minimum score was 7. Finally, the data obtained from the respondents were inserted into SPSS software. The main question of the research used Pearson correlation coefficient and stepwise regression. The results are summarized as follows:

Table 1: descriptive findings of the variables

\begin{tabular}{|c|c|c|c|c|c|}
\hline$\%$ & variables & mean & SD & minimum & maximum \\
\hline \multirow[t]{6}{*}{ Infertility stress } & Infertility stress & 87.5 & 23.42 & 36 & 138 \\
\hline & Social concern & 15.51 & 5.77 & 5 & 28 \\
\hline & Sexual concern & 16.72 & 7.66 & 5 & 30 \\
\hline & Relationship concern & 11.89 & 5.65 & 5 & 26 \\
\hline & Rejection of childfree lifestyle & 15.35 & 5.41 & 4 & 24 \\
\hline & Need for parenthood & 28.03 & 7.20 & 8 & 36 \\
\hline \multirow[t]{2}{*}{ Coping style } & Problem-based coping & 14.85 & 2.93 & 5 & 20 \\
\hline & Emotion-based coping & 13.98 & 3.43 & 4 & 20 \\
\hline \multirow[t]{4}{*}{ Perceived support } & Perception support & 22.3 & 5.87 & 6 & 30 \\
\hline & Family support & 8.04 & 2.37 & 2 & 10 \\
\hline & Friends support & 6.28 & 2.78 & 2 & 10 \\
\hline & Others' support & 8.02 & 2.39 & 2 & 10 \\
\hline \multirow[t]{4}{*}{ Marital satisfaction } & Marital satisfaction & 33.8 & 7.09 & 3 & 44 \\
\hline & satisfaction & 19.88 & 4.05 & 0 & 10 \\
\hline & stability & 7.51 & 2.63 & 0 & 10 \\
\hline & Agreement & 6.45 & 1.98 & 1 & 10 \\
\hline
\end{tabular}


Table 1 indicates the descriptive statistical indices like mean and standard deviation for research variables and their dimensions.

Table 2. correlationcoefficients between the variables and marital satisfaction

\begin{tabular}{|l|l|c|}
\hline Variables & Dimensions & Marital satisfaction \\
\hline \multirow{4}{*}{ Infertility stress } & Total infertility stress & $-0.35^{\star *}$ \\
\cline { 2 - 3 } & Social concern & -0.21 \\
\cline { 2 - 3 } & Sexual concern & -0.40 \\
\cline { 2 - 3 } & Relationship concern & -0.48 \\
\cline { 2 - 3 } & Rejection of childfree lifestyle & -0.07 \\
\cline { 2 - 3 } & Need for parenthood & -0.11 \\
\hline \multirow{4}{*}{ Coping style } & Problem-based coping & 0.13 \\
\cline { 2 - 3 } & Emotion-based coping & -0.31 \\
\hline \multirow{5}{*}{ Social support } & Total perception support & 0.35 \\
\cline { 2 - 3 } & Family support & 0.21 \\
\cline { 2 - 3 } & Friends support & 0.25 \\
\cline { 2 - 3 } & Important others' support & 0.37 \\
\hline
\end{tabular}

Table 2 contains information on correlation coefficient of independent and dependent variables. the results show that infertility stress and emotion-based coping strategy has a negative and significant relationship with marital satisfaction $(0.01)$. on the other hand, perceived social support has a positive and significant relationship with marital satisfaction in infertile women.

Table 3. Prediction of marital satisfaction by perceived support, infertility stress, and coping styles

\begin{tabular}{|c|c|c|c|c|c|c|c|c|c|}
\hline \# & Predicting variable & $\mathbf{R}$ & $\mathbf{R}^{2}$ & Df & $\mathrm{F}$ & B & Beta & $t$ & Sig \\
\hline 1 & Relationship concern & 0.48 & 0.23 & (199( & $61.07^{\star}$ & -0.61 & -0.48 & -7.81 & 0.0001 \\
\hline 2 & $\begin{array}{l}\text { Relationship concern } \\
\text { Important others' support }\end{array}$ & 0.55 & 0.30 & ) 2 & $42.13^{*}$ & $\begin{array}{l}-0.52 \\
0.77\end{array}$ & $\begin{array}{l}-0.42 \\
0.26\end{array}$ & $\begin{array}{l}-6.73 \\
4.24\end{array}$ & 0.0001 \\
\hline 3 & $\begin{array}{l}\text { Relationship concern } \\
\text { Important others }\end{array}$ & 0.57 & 0.33 & ( 197( & 31.92 & $\begin{array}{l}-0.5 \\
0.66 \\
\end{array}$ & $\begin{array}{l}-0.39 \\
0.22\end{array}$ & $\begin{array}{l}-6.56 \\
0.63 \\
\end{array}$ & 0.0001 \\
\hline 4 & $\begin{array}{l}\text { Relationship concern } \\
\text { Important others } \\
\text { Emotion-based coping }\end{array}$ & 0.59 & 0.35 & 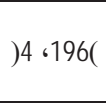 & $26.16^{*}$ & $\begin{array}{l}-0.44 \\
0.68 \\
-0.32 \\
\end{array}$ & $\begin{array}{r}-0.35 \\
0.23 \\
-0.15 \\
\end{array}$ & $\begin{array}{l}-5.56 \\
3.75 \\
-2.51 \\
\end{array}$ & $\begin{array}{l}0.0001 \\
0.0001 \\
0.013 \\
\end{array}$ \\
\hline 5 & $\begin{array}{l}\text { Relationship concern } \\
\text { Important others } \\
\text { Emotion-based coping } \\
\text { Need for parenthood }\end{array}$ & 0.60 & 0.36 & 195 ( & $22.10^{*}$ & $\begin{array}{l}-0.49 \\
0.65 \\
-0.37 \\
0.13 \\
\end{array}$ & $\begin{array}{l}-0.39 \\
0.22 \\
-0.18 \\
0.13 \\
\end{array}$ & $\begin{array}{l}-5.96 \\
3.65 \\
-2.85 \\
2.04 \\
\end{array}$ & $\begin{array}{c}0.0001 \\
0.0001 \\
0.005 \\
0.04 \\
\end{array}$ \\
\hline 6 & $\begin{array}{l}\text { Relationship concern } \\
\text { Important others } \\
\text { Emotion-based coping } \\
\text { Need for parenthood } \\
\text { Sexual concern }\end{array}$ & 0.62 & 0.38 & ) 6 & $19.96^{*}$ & $\begin{array}{l}-0.41 \\
0.64 \\
-0.32 \\
0.194 \\
-0.18\end{array}$ & $\begin{array}{l}-0.32 \\
0.21 \\
-0.15 \\
0.20 \\
-0.19\end{array}$ & $\begin{array}{c}-4.51 \\
3.59 \\
-2.47 \\
2.89 \\
-2.50\end{array}$ & $\begin{array}{l}0.0001 \\
0.0001 \\
0.014 \\
0.004 \\
0.013 \\
\end{array}$ \\
\hline
\end{tabular}

Table 3 contains the results of stepwise regression analysis for prediction of marital satisfaction by independent variables. the results show that marital satisfaction in infertile women can be predicted by subscales like relationship concern, important others support, emotion-based coping style, need for parenthood and sexual concern.

\section{Conclusion and Discussion}

An analysis of the results obtained forrelationship between independent variables and dependent variable of this research showed that infertility stress and emotion-based coping strategy has a negative and significant relationship with marital satisfaction in infertile women. This means an increase in infertility stress and use of emotion-based coping strategies results in reduction of marital satisfaction and decreasing infertility stress and use of emotion-based coping strategies by 
infertile women can increase their marital satisfaction. Furthermore, the results showed that perceived social support by infertile women has a positive and significant relationship with marital satisfaction. In other words, an increase in the level of perceived social support in such individuals increases their marital satisfaction. Other findings showed that some of the subscales of dependent variables including relationship concern, important others' support, emotion-based coping strategy and need for parenthood and sexual concern are able to predict marital satisfaction in infertile women in a significant level. Newton et al (1999) also showed that individuals who experience high levels of infertility stress have low levels of marital satisfaction and in this research, relationship concerns and sexual concerns were better predictors. This is consistent with the results of the present research. Infertility has many negative psychological consequences for couples. When a woman is diagnosed as being infertile, she is confronted with different labels and dissatisfactions. This makes her blame herself and take on the responsibility for infertility. Marital relationship itself can be used as a barrier against this stressful event of life. Weakness in marital relationship, reduction in sexual satisfaction, threat of feminine or masculine perceptions can increase stress. Stress experience reduces couples' satisfaction with their sexual and marital relations. This creates a cycle in which the elements improve each other. Stress reduces satisfaction with relations and dissatisfaction can increase stress. Infertile women are very sensitive to remembering others' ideas and questions abouttheir infertility. When pregnancy is delayed, the relatives may bring the couple under pressure to have a baby and this may cause worry. A sense of solitude and isolation in a family environment and the fact that they cannot continue their social activities as before may bring stress. These factors brings negative attitude towards social acceptance because they are sensitive to this attitude and acceptance of relatives. They believe that when infertility is eliminated, they will have more control over their lives. This sense of absence of control and absence of social acceptance along with the created stress may reduce the woman's self-confidence, she may feel frustrated and this sense of frustration may affect the marital relationship. Social support is useful for an infertile woman because it affects cognitive evaluation and selection of effective coping styles. When needed, women express their emotions and prepare their forces for receiving support. Since women discuss about infertility more than men, they may seek for social support in order to be able to tolerate chronic diseases. Positive evaluation of consequences and the fact of not feeling oneself improves marital relations and brings a sense of satisfaction. This result is consistent with Milet (2002) and lbrahimi et al (2002) results. The findings of studies conducted by Lin et al (2011); Mazaheri et al (2001), Sayyadi (2008), Besharat (2006); Rao et al (2003) were also consistent with the results of the present research. Individuals use emotion-based coping style and enter a vicious circle and their self-confidence is reduced due to failure to cope with psychological pressures and their psychological health is threatened (Sayyadi, 2008). Therefore, it can be said that the research hypothesis which dealt with the presence of a significant relationship between infertility stress, coping styles and perceived social support with marital satisfaction in infertile women was verified.

\section{Research Restrictions}

- use of minimum sample size

- the sample was limited to only infertile women

- ignorance of different infertility periods and treatments conducted

\section{Recommendations}

- investigation of population of infertile men in similar future studies

- differentiation between different infertility periods and treatments for investigation of stress and compatibility

\section{References}

Ahmadi, Kh; Azad MarzAbadi, A. and MollaZamani, A. (2005). Investigation of the state of marriage and marital compatibility among Army employees, military medicine, number 7 (2), pp: 141-152.

Akouchkian, Sh; RouhAfza, H; HasanZadeh, A. and Mohammad Sharifi, H. (2008).Relationship between social support and coping strategies with stress in nurses of psychology department.Journal of Guilan Medical Sciences University, number 69, 18 $8^{\text {th }}$ period, 41-46.

Alizadeh, T; Farahani, M; ShahrAray, M. and Alizadegan, Sh. (2005).Relationship between self-esteem and control resource and infertility stress in infertile women and men. Quarterly of fertility and infertility, 194-204.

Andrews, F.M.; Abbey, A. \& Halman, L.J. (1992), Is fertility Problem stress different? Fertil Steril, 57, 1247-1253.

BaghbanSichani, A. AhmadiAlounAbadi, S. A. and Gholamian, F. (2007). A review of marital quality viewpoints and factors affecting 
them.Papers collection of research week, 2007.

Benazon, N.; Wright, J. \& Sabourin, S. (1992), Stress, Sexual Satisfaction and Marital Adjustment in Infertile Couples, Sex \& Marital Therapy, 18(4), 273-84.

Benyamini,Y., Gefen-Bardarian,y., Gozlan, M., Tabiv, G., Shiloh, Sh; \& Kokia,E.(2008). Coping Specificity: The case of women coping with infertility treatments, Psychology and Health, 23(2), 221-241.

Delongis, A.; Holtzman, S.(2005). Coping in Context:The Role of Stress, Social Support, and Personality in Coping. Journal of Personality 73:6.

Drageset, S.; \& Lindstrqm, T.C. (2005). Coping with a possible breast cancer diagnosis: demographic factors and social support. Journal of Advanced Nursing 51(3),217-226

Farahani, M. N. (2001). Psychological aspects of coping and compatibility with infertility and psychologist's role. Quarterly of fertility and infertility, pp: 53-58.

Gibson, D. M., \& Myers, J. E.(2002). The effect of social coping resources and growth-fostering relationships on infertility stress in women. Journal of Mental Health Counseling, 24(1), 68-80.

JafarNejad, P; Farzad, V; Moradi, A. and Shokri, A. (2004).An investigation of relationship between five big personality factors, coping styles and psychological health in bachelor degree students. Journal of psychology and educational sciences, $35^{\text {th }}$ year, number 1, pp: 51-74.

KaramiNouri, R; Akhondi, M. and BehjatiArdakani, Z. (2001).Socio-psychological aspects of infertility from Iranian physicians' viewpoints. Quarterly of fertility and infertility, pp: $14-26$.

Lee-Baggley, D., Preece, M., \& Delongis, A.(2005). Coping with Interpersonal Stress: Role of Big Five Traits. Journal of Personality, 73:5 .1142-1180 .

Maillet, M. H.(2002). Infertility and Marital Adjustmen, the Influence of Perception of Social Support, Privacy Preference and Level of Depression. Submitted to the Graduate Faculty of the Louisiana State University and Agricultural and Mechanical College in partial fulfillment of the requirements for the degree of Doctor of Philosophy In The School of Social Work..

Mollazadeh, J; Mansour, M; Ejehi, J. and Kiamanesh, A. (2002).Marital compatibility and coping styles in martyrs children.Journal of psychology, number 3, 23, sixth year.

Mollayeenejad, M; Jafar Pour Alavi, M; Jahan Far, Sh.And JamshidiOwrak, R. (2000). Relationship between marital compatibility and tension (stress) resulted from infertility in women who referred to infertility treatment center in Isfahan City, 2000, quarterly of fertility and infertility, 2 (1), continuous. 5, pp: 26-39.

Mazaheri, M; Keighobadi, F; Faghihlmani, Z; Ghashang, N. and Pato, M. (2001).Problem-solvingmethods and marital compatibility in infertile and fertile couples.Quarterly of fertility and infertility.

Newton, Ch., Sherrard, W., \& Glovac, I. (1999). The fertility problem Inventory measuring perceived infertility-related stress: Fertility \& Sterility, Vol. 73, No. 1, 54-62.

O'Brien, T . B., \& Delongis, a.(1996). The interactional context of problem-, emotion-, and relationship-focused coping: The role of the Big Five personality factor. Journal of Personality, [ Special Issue: Personality and Coping ], 64, 775-813.

Pasch, L.A., Dunkel-Schetter,C., \& Christensen, A.(2002). Differences between husbands' and wives'approach to infertility affect marital communication and adjustment. Fertility And Sterility, Vol. 77, No. 6, 41-70.

Peterson, B . D.(2002).Examining The Individual and Dyadic Coping Processes of Men and Women in Infertile Couples and Their Relationship to Infertility Stress, Marital Adjustment, and Depression.

Shokri, A. (2009). A comparison of the model of causal relations of causes and consequences of academic stress of female and male students in collectivist and individualist cultural paradigms.PhD thesis, Khwarazmi University.

Sollner,W., Zschocke, I., Zingg-Schir, M., Stein, B., Rumpold, G., Fritsch, P., \& Augustin, M.(1999). Interactive Patterns of Social Support and Individual Coping Strategies in Melanoma Patients and Their Correlations with Adjustment to Illness.Psychosomatics 40:3.

Wiegel, D . J., Ballard, R., \& Deborah, S.(1999). How couples maintain marriages. Journal of Family Relations, 48(3): 263-270.

Yaghmayee, F; Mohammadi, Sh.And AlaviMajd, H. (2009).Design and psychometry" infertile couples' lives quality questionnaire", quarterly of fertility and infertility.Pp: 137-143. 